\title{
Ten centre trial of artificial surfactant (artificial lung expanding compound) in very premature babies
}

\author{
TEN CENTRE STUDY GROUP
}

\begin{abstract}
A protein free artificial surfactant (artificial lung expanding compound; ALEC) composed of dipalmitoylphosphatidylcholine and phosphatidylglycerol was assessed for its effect on the main complications of prematurity in a prospective two stage randomised trial of 328 unselected babies delivered at between 25 and 29 weeks of gestation. Babies were randomised to receive approximately $100 \mathrm{mg}$ artificial surfactant suspension or $1 \mathrm{ml}$ saline. This was given at birth into the pharynx with up to three more endotracheal doses if the baby was intubated during the first day. Treatment with artificial surfactant reduced the neonatal mortality from $27 \%$ to $14 \%$, the incidence of parenchymal brain haemorrhages from $24 \%$ to $16 \%$, and the severity of the respiratory distress syndrome. In the first 10 days babies treated with artificial surfactant who survived averaged 19 hours less in $>30 \%$ oxygen, 20 hours less ventilation, and 17 hours less supplemental oxygen. Artificial surfactant had no effect on the incidence of pneumothoraces, pulmonary interstitial emphysema, patent ductus arteriosus, or postnatal infections and no serious side effects.
\end{abstract}

Artificial surfactant (ALEC) given to very premature babies

TRIAL COllaborators: Dr D Lloyd, Dr P Duffty, Aberdeen Maternity Hospital; Dr G Durbin, Dr I Morgan, Birmingham Maternity Hospital; Dr C Morley,

Dr A Greenough, Dr M South, Cambridge Rosie Maternity Hospital; Dr R

Hume, Dr T Marshall, Edinburgh Simpson Memorial Maternity Pavilion; Dr

T Turner, Dr A Sutton, Glasgow Queen Mother's Hospital; Dr A Greenough, Sister J Poole, Dr H Gamsu, King's College Hospital, London; Dr R Cooke, Dr J Rennie, Liverpool Maternity Hospital; Dr E Hey, Newcastle Princess Mary Maternity Hospital; Dr S Thurlbeck, Dr N McIntosh, St George's Hospital, London; Dr P Dear, Dr D Wheeler, St James's University Hospital, Leeds; Dr S Gore, MRC Biostatistics Unit, Cambridge; Mr N Miller, Dr A Bangham, AFRC Institute of Animal Physiology, Babraham.

Correspondence to: Dr C J Morley, Department of Paediatrics, Addenbrooke's Hospital, Cambridge CB2 2QQ. at birth significantly reduces their mortality and the respiratory support needed and should prove a valuable addition to treatment.

\section{Introduction}

Animal or human surfactant extracts placed into the trachea at birth or when respiratory failure is present improve the oxygenation of premature babies and reduce the incidence of severe complications of prematurity. ${ }^{1-6}$ "Natural" surfactants, however, may be contaminated with proteins or microbes. A protein free artificial surfactant prepared as a crystalline suspension of phospholipids in cold saline (artificial lung expanding compound; ALEC) has therefore been devised which mimics the monolayer properties of natural surfactant. Details of its formulation and properties and experience of its use have been reported..$^{7-13}$

Two Cambridge based studies have assessed the effect of artificial surfactant given to very premature babies at birth. The first started in September 1979 and used one $25 \mathrm{mg}$ dose of surfactant powder given to intubated babies of under 35 weeks' gestation at birth. At publication in January $1981^{10}$ the mortality was reduced from $24 \%$ (8/33 cases) to nil $(0 / 22)$. The study continued to January 1982 , when the overall mortality was reduced from $22 \%$ (17/78) to $4 \%(2 / 53) .^{13}$ The study was criticised, however, for not being randomised. ${ }^{14}$ The second study, a randomised controlled trial in Cambridge and Nottingham, ran from January 1982 to May $1985 .^{13}$ This used up to $100 \mathrm{mg}$ artificial surfactant suspended in $1 \mathrm{ml}$ cold saline with $1 \mathrm{ml}$ saline as the control substance. Babies were given one dose into the pharynx at birth and up to three further doses if they were intubated during the next 24 hours. That trial was designed to compare respiratory support in the two groups and to randomise 360 babies of less than 35 weeks' gestation. We estimated that the trial would recruit only $90-100$ babies of under 30 weeks' gestation and would have only a 50:50 chance of detecting even a halving in their mortality. Babies of 30-34 weeks' gestation already have a low neonatal death rate (about 4\%). By May 1984, at interim analysis, data had been collected on 94 babies of 25-29 weeks' gestation; in this group treatment with artificial surfactant had reduced the mortality from $38 \%$ (18/47 cases) to $21 \%$ (10/47). To 
show conclusively whether artificial surfactant was beneficial in this gestational age group a large multicentre trial was carried out. This paper reports the results.

\section{Subjects and methods}

\section{TRIAL DESIGN}

The Cambridge and Nottingham trial was extended to define the effect of artificial surfactant on mortality in babies of 25 to 29 weeks of gestation. This group has a high incidence of the respiratory distress syndrome and a reasonable chance of survival. Secondary targets were the effects on respiratory treatment, severity of the respiratory distress syndrome, and other complications of prematurity. a new trial had been started some 600 babies would have been required to achieve similar power. A trial including so many babies of between 25 and 29 weeks of gestation would have been very difficult to complete.

Theoretically, extending the trial might have led to results favouring artificial surfactant because the trial was continued in a group of babies in whom artificial surfactant appeared to be effective. Several points, however, should be borne in mind. Firstly, when setting the trial targets most of the collaborators did not know the results of the first stage. Secondly, clinical trials are always based on information which suggests that the trial might be worth while. Thirdly, there are many chance factors which alter the results of a trial; these are minimised when large randomised groups are compared. Lastly, the results of a trial are only estimates of the real effect. Confidence intervals taking into account the possible effect of extending the trial may be calculated theoretically or by simulation. Essentially the procedure slightly reduces the estimated difference in death rates and widens the $95 \%$ confidence interval to $2 \times 2.178$ standard errors instead of $2 \times 1.96$ standard

TABLE I-Basic data and antenatal factors which might influence outcome

\begin{tabular}{|c|c|c|c|c|c|c|}
\hline & \multicolumn{2}{|c|}{ Overall } & \multicolumn{2}{|c|}{ 25-26 Weeks } & \multicolumn{2}{|c|}{ 27-29 Weeks } \\
\hline & ALEC & Control & ALEC & Control & ALEC & Control \\
\hline No randomised & 164 & 164 & 46 & 40 & 118 & 124 \\
\hline Ineligible & 5 & 15 & 3 & 8 & 2 & 7 \\
\hline Eligible & 159 & 149 & 43 & 32 & 116 & 117 \\
\hline Non-Cambridge eligible & 89 & 81 & 25 & 17 & 64 & 64 \\
\hline \multicolumn{7}{|l|}{ Eligible babies: } \\
\hline Mean birth weight in grams (SD) & $1093(310)$ & $1070(251)$ & $826(118)$ & $809(132)$ & $1192(300)$ & $1141(228)$ \\
\hline Mean gestational age in weeks (SD) & $27 \cdot 6(1 \cdot 3)$ & $27 \cdot 6(1 \cdot 3)$ & $25 \cdot 7(0 \cdot 4)$ & $25 \cdot 5(0 \cdot 5)$ & $28 \cdot 3(0 \cdot 8)$ & $28 \cdot 1(0 \cdot 8)$ \\
\hline Boys (\%) & 51 & 54 & 72 & 59 & 43 & 52 \\
\hline Membrane rupture $>2$ days $(\%)$ & 23 & 19 & 26 & 25 & 22 & 17 \\
\hline Pre-eclampsia (\%) & 17 & 21 & 16 & 13 & 17 & 23 \\
\hline Caesarean section (\%) & 58 & 62 & 44 & 38 & 63 & 69 \\
\hline Labour (\%) & 67 & 60 & 81 & 81 & 61 & 55 \\
\hline Steroids (\%) & 11 & 14 & 12 & 12 & 11 & 14 \\
\hline$\beta$ Stimulants (\%) & 26 & 32 & 35 & 50 & 23 & 27 \\
\hline Multiple birth (\%) & 19 & 29 & 21 & 31 & 19 & 28 \\
\hline Intrauterine growth retardation (\%) & 15 & 15 & 16 & 3 & 15 & 19 \\
\hline Born infected $\star(\%)$ & 4 & 6 & 7 & 9 & 3 & 5 \\
\hline
\end{tabular}

ALEC $=$ Artificial lung expanding compound (surfactant)

$\star$ Baby with bacteria cultured in blood taken at delivery.

TABLE II-Mortality by gestational age and centre strata. (Denominators for eligible babies only; percentages in parentheses)

\begin{tabular}{|c|c|c|c|c|c|}
\hline \multirow{2}{*}{$\begin{array}{c}\text { Gestational } \\
\text { age } \\
\text { (weeks) }\end{array}$} & \multirow[b]{2}{*}{ Centre } & \multicolumn{2}{|c|}{ Neonatal mortality } & \multicolumn{2}{|c|}{ Deaths in neonatal unit } \\
\hline & & ALEC & Control & ALEC & Control \\
\hline $25-26$ & $\left\{\begin{array}{l}\text { Cambridge } \\
\text { Non-Cambridge }\end{array}\right.$ & $\begin{array}{l}5 / 18(28) \\
8 / 25(32)\end{array}$ & $\begin{array}{l}8 / 15(53) \\
7 / 17(41)\end{array}$ & $\begin{array}{r}8 / 18(44) \\
11 / 25(44)\end{array}$ & $\begin{array}{l}9 / 15(60) \\
7 / 17(41)\end{array}$ \\
\hline $27-29$ & $\left\{\begin{array}{l}\text { Cambridge } \\
\text { Non-Cambridge }\end{array}\right.$ & $\begin{array}{l}3 / 52(6) \\
7 / 64(11)\end{array}$ & $\begin{array}{l}10 / 53(19) \\
15 / 64(23)\end{array}$ & $\begin{array}{l}3 / 52(6) \\
8 / 64(13)\end{array}$ & $\begin{array}{l}11 / 53(21) \\
17 / 64(27)\end{array}$ \\
\hline \multicolumn{2}{|l|}{ Total } & $23 / 159(14)$ & $40 / 149(27)$ & $30 / 159(19)$ & $44 / 149(30)$ \\
\hline \multicolumn{2}{|c|}{ Significance } & \multicolumn{2}{|c|}{$\chi^{2}$ (accounting for strata) $=9.22 ; p<0.002$} & \multicolumn{2}{|c|}{$\chi^{2}$ (accounting for strata) $=6.95 ; \mathrm{p}<0.01$} \\
\hline
\end{tabular}

^Non-Cambridge $=$ All centres other than Cambridge.

At a meeting to plan the trial 12 collaborators were asked their opinions about the possible effect of artificial surfactant on mortality in babies of 25 to 29 weeks of gestation. Without knowing the results of the Cambridge and Nottingham trial they suggested that it might reduce mortality from $36 \%$ to $28 \%$. When combined with the opinions of the three Cambridge collaborators who knew the current mortality in the trial the consensus was that a plausible effect of artificial surfactant would be a reduction in mortality from $36 \%$ to $27 \%$. A total of 300 eligible babies were required to have a conditional power of $74 \%$ for detecting such an effect. This was conditional on including the data in hand from babies of 25 to 29 weeks of gestation in the Cambridge and Nottingham trial. This target would be achieved in one year by collaboration from 10 neonatal units, each randomising about 20 babies, together with the babies of 25 to 29 weeks of gestation from the Cambridge wing of the Cambridge and Nottingham trial. Nottingham did not join this trial.

Extending the Cambridge and Nottingham trial to the multicentre trial was valid because throughout both stages babies were randomised using the same protocol and the Cambridge and Nottingham trial was not large enough to show convincingly clinically significant differences in mortality. If errors (see below). The appendix formalises extending the Cambridge and Nottingham trial to multicentre collaboration and presents the case for debiased confidence intervals, if only extended trials came to publication.

\section{PROTOCOL}

The protocol was identical with that for the Cambridge and Nottingham trial $^{13}$ except for the different gestational age criteria and the exclusion of non-resuscitated babies. Babies of 25 to 29 weeks of gestation inclusive were born in hospital, a trial collaborator being present at delivery. Gestation was calculated from the available information. Babies were individually randomised from envelopes immediately before delivery and registered with the biostatistics unit by telephone. Using equipment kept at $4^{\circ} \mathrm{C}$, surfactant suspension was prepared just before birth by hand shaking approximately $100 \mathrm{mg}$ with $1 \mathrm{ml}$ saline. Controls received $1 \mathrm{ml}$ saline alone. This volume was chosen because it is the volume that many hospitals use for routine endotracheal lavage. As near to the first breath as possible the baby received 
either artificial surfactant or saline into the pharynx so that it might be inhaled. If the baby was intubated for resuscitation a second dose was instilled through the endotracheal tube. If intubated at one and 24 hours third and fourth doses were given. The treatment given was not disclosed to the nurses or doctors caring for the baby. All clinical decisions were taken by the duty paediatric teams. Exclusions were retrospective if the baby was stillborn, resuscitation was not attempted, or the baby had a lethal malformation. The trial was approved by the ethics committee at each hospital. The randomisation ratio was $1: 1$ by blocks of length 2 or 4 within centre with the two gestational age strata 25 and 26 weeks, and 27, 28, and 29 weeks to prevent imbalance in this influential factor. Twenty randomised babies were later confirmed as ineligible; 15 were controls (three in whom resuscitation was not attempted, four stillborn, eight malformed) and five were in the surfactant treatment group (three stillborn, two malformed).

\section{ANALYSIS}

The trial was designed to assess the effect of artificial surfactant (randomly allocated) on mortality regardless of cause. The Cambridge and nonCambridge data are separated for comparison because one third of the babies

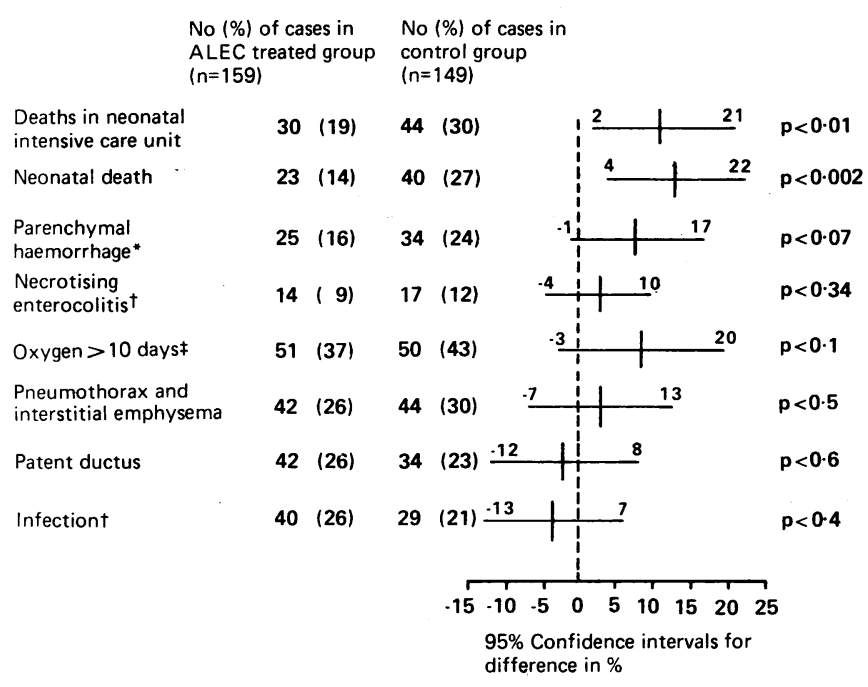

FIG 1-Main complications of prematurity occurring in eligible babies from the two groups and $95 \%$ confidence intervals for differences in percentages. p Values for differences take age strata and centres into account.

^Five ALEC treated babies and six controls not scanned.

†As defined, postnatal infection occurred only after first 24 hours; necrotising enterocolitis did not occur in first 24 hours. Denominators were 152 ALEC treated babies and 139 controls.

$\ddagger$ A total of 138 ALEC treated babies and 117 controls survived 10 days.

were contributed by Cambridge. For analysis the babies were stratified by gestation and centre: $25-26$ weeks Cambridge, $25-26$ weeks non-Cambridge; 27-29 weeks Cambridge, 27-29 weeks non-Cambridge. Any difference in the incidence of complications between these strata is reflected in the Mantel-Haenszel analysis, ${ }^{15}$ from which the $\chi^{2}$ values and confidence intervals $\left(1.96 \times\right.$ standard error) were derived..$^{16} 17$

No statistical adjustment was made for the two stage trial design except for mortality, for which both adjusted and unadjusted confidence intervals are cited. Throughout $p$ values are not adjusted.

Regression analysis for neonatal mortality, hours of ventilation, hours receiving oxygen, and hours receiving $>30 \%$ oxygen during the first 240 hours for survivors at 10 days compared the effect of artificial surfactant with the effect of being female or having one extra week of gestation. Adjustment was also made for centre and multiple birth because of imbalance in this factor. Ten days was chosen because effects of surfactant should be apparent during this time and it reduced the data collected.

Before the trial data from previous studies were used to grade the respiratory distress syndrome by the number of hours each baby received $>30 \%$ oxygen in the first 10 days: $<24$ hours, none; $24-47$ hours, mild; $48-120$ hours, moderate; $>120$ hours, severe. Deaths in the first five days were graded as severe respiratory distress syndrome if a baby died receiving $>30 \%$ oxygen. If a baby died after five days the grading was as above. Ventilation was not used in the grading because $80 \%$ of very premature babies are ventilated from birth even though some do not have the

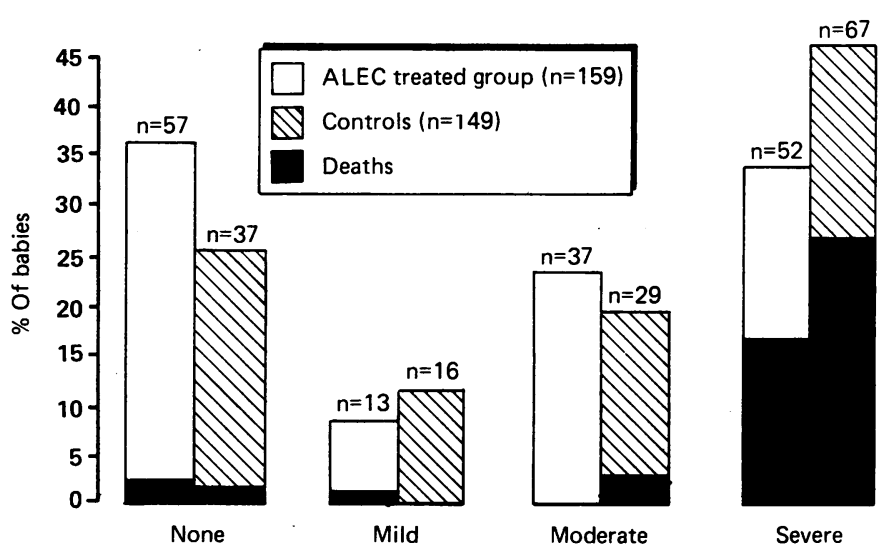

FIG 2-Grades of respiratory distress syndrome and proportions of deaths in ALEC treated and control groups.

$\chi^{2}$ For trend (severity ordered as $\left.0,1,2,3\right)=4.84 ; p<0.03$.

respiratory distress syndrome. An oxygen concentration of $30 \%$ was chosen as cut off because many premature babies require low concentrations of oxygen for long periods to treat problems unrelated to the respiratory distress syndrome.

The analysis compared babies in the groups to which they were randomised. Four babies were not treated as randomised; a pair of twins was muddled, one baby was given saline instead of artificial surfactant, and one envelope was wrongly coded.

\section{Results}

Three hundred and twenty eight babies were randomised to receive saline alone or the artificial surfactant (ALEC), of whom 20 were ineligible for further analysis. Table I shows the groups by gestational age and the distribution of antenatal factors which could influence the incidence of complications. There was a reasonable balance between groups, except for an excess of multiple births among the controls. This was allowed for in the regression analyses. The number of babies randomised in the 10 centres were: Aberdeen 27; Birmingham 17; Edinburgh 12; Glasgow 21; King's, London, 24; Leeds 27; Liverpool 22; Newcastle 19; St George's, London, 12; Cambridge 147 (of these, 124 were randomised in the Cambridge and Nottingham trial, 77 before the decision to extend).

Figure 1 shows the main complications of prematurity with $95 \%$ confidence intervals and $p$ values from the Mantel-Haenszel analysis. The results between the strata were not significantly different for any complication, though given the numbers studied the $\chi_{(3)}^{2}$ test for heterogeneity had low power. ${ }^{17}$

\section{MORTALITY}

Treatment with artificial surfactant reduced neonatal mortality (first 28 days) from $27 \%(40 / 149$ cases) to $14 \%(23 / 159)(p<0.002)$, the $95 \%$ confidence interval being four to 22 additional neonatal survivors per 100 surfactant treated infants. There were no significant differences with treatment between Cambridge (controls 26\% (18/68), surfactant group 11\% $(8 / 70)$ ) and non-Cambridge centres (controls $27 \%$ (22/81), surfactant group $17 \%(15 / 89)$ ) and by gestation (25-26 weeks: controls $47 \%(15 / 32)$, surfactant group $30 \%$ (13/43); $27-29$ weeks: controls $21 \%$ (25/117), surfactant group $9 \%(10 / 116)$ ) (table II). The overall effect of artificial surfactant on mortality was equivalent to the babies being older by over one week of gestation and better than being female (table III).

Mortality while in the neonatal unit was reduced from $30 \%$ (44/149 cases) to $19 \%(30 / 159)(p<0.01)$, the $95 \%$ confidence interval being two to 21 extra survivors per 100 treated babies. There were no significant differences with treatment between Cambridge (controls $29 \%$ (20/68), surfactant group 16\% (11/70)) and non-Cambridge centres (controls $30 \%$ (24/81), surfactant group $21 \%(18 / 89)$ ) and by gestation (25-26 weeks: controls $50 \%(16 / 32)$, surfactant group $44 \%$ (19/43); $27-29$ weeks: controls $24 \%$ (28/117), surfactant group $9 \%(11 / 118)$ ) (table II).

If allowance is made for a possible influence from the two stage trial design a more conservative analysis using simulation adjusted $95 \%$ confidence intervals for mortality would be: neonatal mortality, one to 21 additional neonatal survivors per 100 surfactant treated infants; mortality while in the neonatal unit, one less to 19 extra survivors per 100 surfactant treated babies. 
As more surfactant treated than control babies survive more may have complications, which may bias the analysis of these complications against artificial surfactant.

TABLE III-Effect of prognostic factors on neonatal mortality

\begin{tabular}{lccc}
\hline Prognostic factor & Coefficient & SE & p Value \\
\hline ALEC & -0.71 & 0.26 & $<0.005$ \\
Female & -0.31 & 0.27 & $<0.25$ \\
Each additional week of gestational age & -0.50 & 0.10 & $<0.0001$ \\
1st Multiple & -0.03 & 0.44 & NS \\
2nd Or more multiple & -0.17 & 0.39 & NS \\
Non-Cambridge & 0.07 & 0.26 & NS
\end{tabular}

Coefficients (natural logarithm of relative risk of neonatal death) give comparative effect of each prognostic factor on chance of neonatal death. Baseline for analysis with each factor having coefficient of 0 is: control, male, gestation 27.6 weeks (average of trial), singleton, born in Cambridge. To give risk score for any baby coefficients may be added-for example, compared with baseline control baby with score of zero a surfactant treated $(-0.71)$ female $(-0.31)$ singleton $(0)$ born one week older $(-0.50)$ in non-Cambridge centre $(0.07)$ would have reduced risk of neonatal death-that is, composite score -1.45 (one quarter of relative risk; exponential $-1 \cdot 45=0 \cdot 23$ ). $(p<0 \cdot 14)$ than the controls. These effects were similar to the reduction produced by one extra week of gestational age (table IV).

Four (3\%) babies in each group required no additional oxygen; $20(13 \%)$ ए surfactant treated babies and $14(9 \%)$ controls needed no ventilation, and 11 (7\%) surfactant treated babies and $13(9 \%)$ controls required less than $30 \%$ oxygen.

\section{PNEUMOTHORAX OR GROSS PULMONARY INTERSTITIAL EMPHYSEMA}

Pneumothorax and gross interstitial emphysema occurred in $26 \%(42 / 159)$ of surfactant treated babies and $30 \%(44 / 149)$ of the controls $\left(\chi^{2}=0.45\right.$; NS $)$ (fig 1).

\section{PATENT DUCTUS ARTERIOSUS}

Patent ductus arteriosus was diagnosed from a classical murmur, bounding pulses, plethoric lung fields, and the need for treatment. A patent ductus was found in $26 \%(42 / 159)$ of the surfactant treated group and $23 \%$ $(34 / 149)$ of the controls $\left(\chi^{2}=0 \cdot 30 ;\right.$ NS) (fig 1$)$.

TABLE IV-Effect of prognostic factors on respiratory support in first 10 days. Survivors only

\begin{tabular}{|c|c|c|c|c|c|c|c|c|c|}
\hline \multirow[b]{2}{*}{ Prognostic factor } & \multicolumn{3}{|c|}{ Hours of oxygen } & \multicolumn{3}{|c|}{ Hours of $>30 \%$ oxygen } & \multicolumn{3}{|c|}{ Hours of intermittent positive pressure ventilation } \\
\hline & Coefficient & SE & p Value & Coefficient & SE & p Value & Coefficient & SE & $\mathrm{p}$ Value \\
\hline $\begin{array}{l}\text { ALEC } \\
\text { Female } \\
\text { Each additional week of gestational age } \\
\text { Ist Multiple } \\
\text { 2nd Or more multiple } \\
\text { Non-Cambridge }\end{array}$ & $\begin{array}{r}-16 \cdot 6 \\
-5 \cdot 1 \\
-20 \cdot 9 \\
-9 \cdot 9 \\
42 \cdot 7 \\
-1 \cdot 5\end{array}$ & $\begin{array}{r}11 \cdot 1 \\
11 \cdot 3 \\
4 \cdot 4 \\
17 \cdot 6 \\
16 \cdot 4 \\
11 \cdot 3\end{array}$ & $\begin{array}{l}<0 \cdot 14 \\
\text { NS } \\
<0 \cdot 0001 \\
\text { NS } \\
<0 \cdot 01 \\
\text { NS }\end{array}$ & $\begin{array}{r}-18 \cdot 7 \\
-4 \cdot 7 \\
-16 \cdot 8 \\
-8 \cdot 5 \\
20 \cdot 2 \\
9 \cdot 9\end{array}$ & $\begin{array}{r}9 \cdot 5 \\
9 \cdot 6 \\
3 \cdot 7 \\
15 \cdot 0 \\
14 \cdot 0 \\
9 \cdot 7\end{array}$ & $\begin{array}{l}<0.05 \\
\text { NS } \\
<0.0001 \\
\text { NS } \\
<0.15 \\
\text { NS }\end{array}$ & $\begin{array}{r}-20 \cdot 2 \\
-2 \cdot 1 \\
-31 \cdot 4 \\
-14 \cdot 0 \\
56 \cdot 6 \\
30 \cdot 5\end{array}$ & $\begin{array}{r}10 \cdot 1 \\
10 \cdot 3 \\
4 \cdot 0 \\
16 \cdot 0 \\
15 \cdot 0 \\
10 \cdot 3\end{array}$ & $\begin{array}{l}<0.05 \\
\text { NS } \\
<0.0001 \\
\text { NS } \\
<0.0002 \\
<0.003\end{array}$ \\
\hline Baseline (hours) ${ }^{\star}$ & \multicolumn{3}{|c|}{$197 \cdot 1$} & \multicolumn{3}{|c|}{$128 \cdot 8$} & \multicolumn{3}{|c|}{$183 \cdot 4$} \\
\hline
\end{tabular}

^Baseline is respiratory support required by male singleton control at 25 weeks' gestation in Cambridge.

For explanation of multiple regression analysis see table III. Coefficients may be considered as change in hours of support attributable to each prognostic factor in first 10 days compared with baseline.

\section{PERIVENTRICULAR HAEMORRHAGE}

Parenchymal brain haemorrhages were detected by ultrasonography or at necropsy. Ultrasound grading was not standardised among centres, so haemorrhages were recorded as no bleeding, bleeding but not parenchymal, and parenchymal brain haemorrhage. Five surfactant treated and six control babies were not scanned. The analysis concentrates on parenchymal haemorrhages because these are associated with developmental problems. ${ }^{18}$

The incidence of parenchymal haemorrhages (fig 1) was reduced by surfactant from $24 \%(34 / 143$ cases $)$ to $16 \%(25 / 154)\left(\chi^{2}=3 \cdot 43 ; p=0.06\right)$ with a $95 \%$ confidence interval of one extra to 17 fewer parenchymal haemorrhages per 100 surfactant treated babies. There was no significant heterogeneity among strata $\left(\chi_{(3)}^{2}=4 \cdot 38\right)$ in Cambridge (controls $30 \%(20 / 67)$, surfactant group $14 \%(10 / 70)$ ) and non-Cambridge centres (controls $18 \%$ (14/76), surfactant group $18 \%(15 / 84)$ ) and by gestation of $25-26$ weeks: controls $32 \%(10 / 31)$, surfactant group 33\% (14/42); $27-29$ weeks: controls $21 \%(24 / 112)$, surfactant group $10 \%(11 / 112))$. The incidence of nonparenchymal haemorrhage was $19 \%$ in the two groups.

\section{RESPIRATORY DISTRESS SYNDROME}

Figure 2 shows the grades of respiratory distress syndrome; $36 \%(57 / 159)$ of surfactant treated babies had no respiratory distress compared with $25 \%$ (37/149) of the controls, and $45 \%(67 / 149)$ of the controls had severe respiratory distress compared with $33 \%(52 / 159)$ of the surfactant treated babies. Trend analysis regressing the surfactant treated proportions in each grade on ordered severity was consistent with more surfactant treated babies in the less severe grades $\left(\chi^{2}\right.$ for trend $=4 \cdot 84 ; p<0 \cdot 03$ ).

\section{RESPIRATORY SUPPORT IN FIRST 10 DAYS (SURVIVORS ONLY)}

Surfactant treated babies had on average 19 hours less in $>30 \%$ oxygen $(p<0.05), 20$ hours less ventilation $(p<0.05)$, and 17 hours less oxygen

\section{PROLONGED OXYGEN TREATMENT}

Oxygen treatment beyond 10 days (that is, on the 11th day) was required by $43 \%(50 / 117)$ of the controls and $37 \%(51 / 138)$ of the surfactant treated babies $\left(\chi^{2}=2 \cdot 58\right.$; NS); $95 \%$ confidence interval was three extra to 20 fewer cases per 100 treated babies (fig 1$)$.

\section{NECROTISING ENTEROCOLITIS}

Necrotising enterocolitis was diagnosed when babies had distension and $\stackrel{3}{3}$ bloody stools of no other obvious cause. The incidence in the two groups was similar: controls $12 \%(17 / 139)$, surfactant treated babies $9 \%(14 / 152)$ $\left(\chi^{2}=0 \cdot 90 ;\right.$ NS) (fig 1$)$.

\section{SERIOUS INFECTIONS NOT PRESENT AT BIRTH}

Serious infections that occurred more than 24 hours after delivery included bacteriologically proved meningitis, pneumonia, and septicaemia. Analysis was therefore restricted to babies who survived at least 24 hours The incidence in surfactant treated babies was similar to that in the controls $\left(26 \%(40 / 152) v 21 \%(29 / 139) ; \chi^{2}=0 \cdot 58\right.$, NS). Five babies in each group had pneumonia in the first week. Other infections were due to various different organisms and occurred over many weeks (fig 1).

\section{Discussion}

In the Cambridge and Nottingham trial artificial surfactant (artificial lung expanding compound; ALEC) given to babies 8 of under 30 weeks' gestation significantly reduced the oxygen requirements and ventilatory pressures needed during the first few days $^{13}$ and significantly improved compliance of the respiratory 
system at six hours (data to be published). This trial shows that artificial surfactant reduces the mortality by a third. The trials $w$ ?re designed to assess the effect of artificial surfactant as used in routine clinical practice. Babies entered the trial purely on the basis of gestational age with all the complicating factors of prematurityasphyxia, infection, hydrops fetalis, antepartum haemorrhage, prolonged rupture of the membranes, severe toxaemia, or even with mature lungs. Compared with trials in which babies were selected ${ }^{3-6}$ any effect of artificial surfactant in this trial could be masked by the deleterious effect of the perinatal complications. It therefore gives a more realistic estimate of the clinical benefits of surfactant.

Mortality was chosen as the primary outcome for the trial because it is unambiguous and high enough in very premature babies $(36 \%)$ to allow a reduction to be detected, given reasonable numbers. The trial showed an effect on mortality consistent with that found in other studies of the artificial surfactant (ALEC)..$^{1319}$ It has been suggested that this artificial surfactant is not so effective as natural surfactant preparations. ${ }^{19-21}$ Analysis of the comparative effect on
Giving surfactant to babies at birth means that they are treated before the possible onset of the respiratory distress syndrome. It is important that it should do no harm. Artificial surfactant (ALEC) is unlikely to be harmful because $(a)$ the two components are similar to the phospholipids which are deficient in the premature lung, $(b)$ saturated phospholipids are bacteriostatic, $(c)$ the process by which it is formulated ensures sterility, and $(d)$ there is no protein component which might sensitise the baby. In the trials to date this artificial surfactant appears to be without harmful effects, though larger numbers will be needed for complete assurance. Given the numbers of babies treated rare side effects would not be detected. One baby was reported to have a temporarily blocked endotracheal tube after the instillation of surfactant; though an isolated incident, this might be avoided by delivering the dose in small aliquots.

Combining all the randomised and non-randomised trials of artificial surfactant (ALEC) gives a total of 323 babies who have been treated and 334 controls and shows an overall reduction in mortality of $42 \%$ - that is, from $19 \%(62 / 334)$ to $11 \%(36 / 323)$.

TABLE V—Comparative effect of different surfactant preparations on mortality in prophylactic clinical trials documenting deaths

\begin{tabular}{|c|c|c|c|c|c|c|c|c|}
\hline \multirow[b]{2}{*}{ Reference } & \multirow[b]{2}{*}{ Surfactant } & \multirow{2}{*}{$\begin{array}{c}\text { Gestational } \\
\text { age } \\
\text { (weeks) }\end{array}$} & \multicolumn{2}{|c|}{ Controls } & \multicolumn{2}{|c|}{ Surfactant } & \multicolumn{2}{|c|}{ Reduction in deaths $/ 100$ treated babies } \\
\hline & & & No & $\%$ Dead & No & $\%$ Dead & Reduction & $95 \%$ Confidence interval \\
\hline 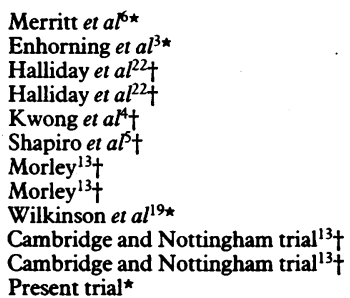 & $\begin{array}{l}\text { Human } \\
\text { Calf } \\
\text { DPPC+HDL } \\
\text { DPPC+HDL } \\
\text { Calf } \\
\text { Calf } \\
\text { ALEC dry } \\
\text { ALEC dry } \\
\text { ALEC dry } \\
\text { ALEC } \\
\text { ALEC } \\
\text { ALEC }\end{array}$ & $\begin{array}{c}24-29 \\
<30 \\
27-29 \\
25,26,30-33 \\
24-28 \\
25-29 \\
<30 \\
31-34 \\
<31 \\
<25,>29 \\
25-29 \\
25-29\end{array}$ & $\begin{array}{r}29 \\
33 \\
14 \\
37 \\
13 \\
16 \\
35 \\
43 \\
12 \\
98 \\
67 \\
149\end{array}$ & $\begin{array}{r}52 \\
21 \\
43 \\
0 \\
15 \\
\\
44 \\
5 \\
17 \\
1 \\
34 \\
27\end{array}$ & $\begin{array}{r}31 \\
39 \\
16 \\
33 \\
14 \\
16 \\
28 \\
25 \\
12 \\
98 \\
69 \\
159\end{array}$ & $\begin{array}{r}16 \\
3 \\
25 \\
6 \\
7 \\
\\
7 \\
7 \\
0 \\
0 \\
4 \\
19 \\
14\end{array}$ & $\begin{array}{c}36 \\
18 \\
18 \\
-6 \\
8 \\
\text { Reported as } \\
37 \\
5 \\
17 \\
-3 \\
15 \\
13\end{array}$ & $\begin{array}{r}14 \text { to } 58 \\
3 \text { to } 33 \\
-15 \text { to } 51 \\
-14 \text { to } 2 \\
-16 \text { to } 32 \\
\text { o difference } \\
18 \text { to } 56 \\
-2 \text { to } 12 \\
-5 \text { to } 39 \\
-7 \text { to } 1 \\
1 \text { to } 31 \\
4 \text { to } 22\end{array}$ \\
\hline
\end{tabular}

True effect of each surfactant lies between $95 \%$ confidence intervals. Control mortality varied greatly among trials owing to different gestational ages and exclusion criteria. Trials by Halliday et $\mathrm{l}^{22}$ and Morley ${ }^{13}$ and Cambridge and Nottingham trial $^{13}$ are divided into two subsets of babies of early and late gestation for comparison with trials studying babies in early gestational age range only. Present trial included babies from Cambridge and Nottingham trial.

DPPC + HDL=Dipalmitoylphosphatidylcholine + high density lipoprotein \#Neonatal mortality.

fOverall mortality.

mortality of different surfactants in different clinical trials (table V), however, showed that when the $95 \%$ confidence intervals for the effect on mortality were compared the protein free artificial surfactant was at least as efficacious in terms of mortality as the more complicated natural surfactant preparations, particularly when gestational age, perinatal complications, and different trial exclusion criteria were taken into account. From a trial of this size we cannot comment confidently on the effect of the artificial surfactant in babies of different gestational ages, though our impression is that it is more effective in babies of 27 to 29 weeks of gestation.

Several studies have shown that exogenous surfactants given either at birth ${ }^{51013}$ or to babies after the onset of respiratory difficulties ${ }^{1346}$ reduce the need for high inspired oxygen concentrations and the incidence of serious complications. The different surfactant preparations used in comparatively small, often preselected groups of babies and the varied timing and doses of surfactant given make it difficult to compare the trials. The effect of artificial surfactant on oxygenation, however, has already been shown, ${ }^{13}$ and in this trial artificial surfactant significantly reduced the severity of the respiratory distress syndrome.

The premature baby's lung is immature in most aspects of its structure and function, with small numbers of poorly vascularised air sacs, difficulty clearing fluid after birth, and an epithelium which is easily damaged, causing protein exudation on to the lung surface, which interferes with gas transfer and inhibits the function of surfactant. Not surprisingly, therefore, trials of exogenous surfactant have invariably been only partially effective in ameliorating neonatal respiratory problems.
The multicentre design of this trial adds robustness to the results, which show that treatment at birth with this protein free artificial surfactant significantly reduces the mortality and respiratory support needed in very premature babies and has no serious side effects. It should therefore be a useful addition to the treatment of premature babies.

We thank the Medical Research Council, University of Cambridge Baby Research Fund, and Allen and Hanburys Ltd. This study would not have been possible without the generous cooperation of the staff in the neonatal intensive care units of the collaborating hospitals.

\section{References}

1 Fujiwara T, Chida S, Watabe Y, Maeta $\mathrm{H}$, Morita T, Abe T. Artificial surfactant therapy in hyaline membrane disease. Lancet 1980; ;:55-9.

2 Hallman M, Merritt TA, Jarvenpaa AL, et al. Exogenous human surfactant for treatment of severe respiratory distress syndrome: a randomized prospective clinical trial. $f$ Pediatr 1985;106: 963-9.

3 Enhorning G, Shennan A, Possmayer F, Dunn M, Chen CP, Milligan J. Prevention of neonatal respiratory distress syndrome by tracheal instillation of surfactant. A randomized clinical trial. Pediatrics 1985;76: 145-53.

4 Kwong SM, Egan EA, Notter RH, Shapiro DL. Double-blind clinical trial of calf lung surfactant extract for the prevention of hyaline membrane disease in extremely premature infants. Pediatrics 1985;76:585-92.

5 Shapiro DL, Notter RH, Morin FC, et al. Double blind, randomized trial of calf lung surfactant extract administered at birth to very premature infants for prevention of respiratory distress

6 Merritt TA, Hallman M, Bloom BT, et al. Prophylactic treatment of very premature infants with human surfactant. $N$ Engl f Med 1986;315:785-90.

7 Bangham AD. Lung surfactant: how it does and does not work. Lung 1987;165:17-25.

8 Morley CJ, Bangham AD, Johnson P, Thorburn GD, Jenkin G. Physical and physiological properties of dry lung surfactant. Nature 1978;271:162-3. 
9 Morley CJ, Bangham AD. Physical properties of surfactant under compression. In: Von Wichert P, ed. Progress in respiratory research. Vol 15. Basle: Karger, 1981:188-93.

10 Morley CJ, Bangham AD, Miller N, Davis JA. Dry artificial surfactant and its effect on very premature babies. Lancet 1981;i:64-8.

11 Bangham AD, Miller NGA, Davies RJ, Greenough A, Morley CJ. Introductory remarks about artificial lung expanding compound (ALEC). Colloids and Surfaces 1984;10:337-41.

12 Morley C, Robertson B, Lachmann B, et al. Artificial surfactant and natural surfactant. Comparative study of the effects on premature rabbit lungs. Arch Dis Child 1980;50:758-65.

13 Morley CJ. The Cambridge experience of artificial surfactant. In: Strang L, ed. Proceedings of the intemational symposium on the physiology and pathophysiology of the fetal and neonatal lung. Lancaster: MTP Press, 1987:255-73.

14 Phelps DL. Dry artificial lung surfactant in prematurity. Lancet 1981;i:556.

15 Pocock SJ. Clinical trials, a practical approach. Chichester: John Wiley and Sons, 1983.

16 Collins R, Yusuf S, Peto R. Overview of randomised trials of diuretics in pregnancy. Br Med $\mathcal{J}$ 1985;290:17-33.
17 Gore SM, Oldham JA. Randomized trials of high versus low dose steroids in renal transplantation. Does the evidence favor a consensus? Transplantation 1986;41:319-27.

18 Thorburn RJ, Lipscomb AP, Stewart AL, Reynolds EOR, Hope PL, Pape KE. Prediction of death and major handicap in very preterm infants by brain ultrasound. Lancet 1981;i:1119-21. 19 Wilkinson A, Jenkins PA, Jeffrey JA. Two controlled trials of dry artificial surfactant: early effects and later outcome in babies with surfactant deficiency. Lancet 1985;ii:287-91.

20 Fujiwara T. Surfactant replacement in neonatal RDS. In: Robertson B, Van Golde B, Batenburg JJ, eds. Pulmonary surfactant. Amsterdam: Elsevier, 1984:479-503.

21 Robertson B, Van Golde LMG. Postscript: surfactant research; current concepts and perspectives for the future. In: Robertson B, Van Golde B, Batenburg JJ, eds. Pulmonary surfactant. Amsterdam: Elsevier, 1984:549-64.

22 Halliday HL, MCClure G, Reid M, Lappin TRJ, Meban C, Thomas PS. Controlled trial of artificial surfactant to prevent respiratory distress syndrome. Lancet 1984;i:476-8.

(Accepted 5 February 1987)

\section{Appendix}

\section{SEQUENTIAL TRIAL EXTENSION AND CASE FOR DEBIASED CONFIDENCE INTERVALS}

Extending the Cambridge and Nottingham trial to multicentre collaboration to compare mortality between surfactant (ALEC) treated and control infants of 25-29 weeks' gestation may be formalised as follows.

Stage 1-Randomised 80 babies.

Continuation criterion-For continuation of trial mortality differential must be at least $1 \mathrm{SE}$ in favour of surfactant. (If surfactant does not reduce mortality there is $16 \%$ risk of continuation; if surfactant reduces mortality by one third the chance of continuation is at least $50 \%$.)

Stage 2-If continuation criterion is met randomise a further 240 babies; otherwise terminate recruitment.

The continuation criterion was not preset for extending to stage 2 , and so the above design has been simulated also with less liberal continuation criteria: $1.28 \mathrm{SE}$ and 1.64 SE to ascertain by how much, on average, the observed reduction in death rates reported in extended trials-that is, those which randomised $80+240$ infants-overestimates the actual difference in death rates. Intuitively the bias will be small when the experimental treatment is effective because it will not be exceptional for the continuation criterion to be met, whereas if a new treatment was not an improvement over the control then we are relying on stage 2 recruitment of a further 240 infants to redress the fortuitous stage 1 differential. Had the stage 2 recruitment $\frac{0}{3}$ been greater then biases would be correspondingly smaller. Thus an appropriate debiasing procedure in sequential trials depends on design and $N$ whether all trials or only extended trials come to publication. Debiased confidence intervals, appropriate if only stage 2 trials were published, have of been derived by simulation of the above design formulation, in which $\searrow$ control mortality was specified as $36 \%, 30 \%$, or $27 \%$ and mortality after surfactant given by nil, a quarter, or one third reduction on the control death rate. Debiased $95 \%$ confidence intervals for the difference in death rates 0 (control-surfactant), besides being shifted towards zero (by roughly two deaths per 100 surfactant treated babies when surfactant induces a one third $\vec{\infty}$ reduction in mortality), have a width $2 \times 2 \cdot 178 \mathrm{SE}$ instead of $2 \times 1.97 \mathrm{SE}$ (table VI).

TABLE VI-Confidence intervals appropriate if only trials extended to stage 2 were published

\begin{tabular}{|c|c|c|c|c|c|c|}
\hline \multirow[b]{3}{*}{ Outcome } & & & \multicolumn{4}{|c|}{$95 \%$ Confidence interval reduction in deaths $/ 100$ babies } \\
\hline & \multicolumn{2}{|c|}{ Death rates $(\%)$} & \multicolumn{2}{|r|}{ Biased } & \multicolumn{2}{|r|}{ Unbiased } \\
\hline & Control & ALEC & Reduction & Confidence interval & Reduction & Confidence interval \\
\hline $\begin{array}{l}\text { As randomised, no exclusions } \\
\text { As randomised, eligible babies } \\
\text { As randomised, eligible babies, neonatal deaths }\end{array}$ & $\begin{array}{l}36 \\
30 \\
27\end{array}$ & $\begin{array}{l}21 \\
29 \\
14\end{array}$ & $\begin{array}{l}15 \cdot 0 \\
11 \cdot 0 \\
13 \cdot 0\end{array}$ & $\begin{array}{l}6 \text { to } 24 \\
2 \text { to } 21 \\
4 \text { to } 22\end{array}$ & $\begin{array}{r}13 \cdot 5 \\
9 \cdot 0 \\
11 \cdot 5\end{array}$ & $\begin{array}{r}3 \text { to } 24 \\
-1 \text { to } 19 \\
1 \text { to } 21\end{array}$ \\
\hline
\end{tabular}

\section{YEARS AGO}

MR. JUSTICE KAY, in announcing judgment in a case brought by a seller of quack medicines against one of the same fraternity for the infringement of trade mark, said lest either party should be tempted to make the judgment a useful medium for advertising his article, he hoped he would add to the advertisement the following intimation, "No one should use this preparation except under medical advice.” (British Medical Fournal 1887;ii:1121.)

As the science of medicine becomes more differentiated, new terms come into use, and there is a tendency to restrict more and more the use of the older ones. This, although a great saving of trouble to the expert, occasionally causes some confusion to the novice, or to those who have allowed their knowledge to fall behind the time. Some years ago the terms amaurosis and glaucoma were frequently applied to conditions to which no one now would attach them. There is now a tendency to restrict further the application of the term hemiopia, and to employ it only for cases in which the lesion is obviously not intra-ocular. The loss of one half of the visual field may of course occur from an intra-ocular lesion, such as a haemorrhage, or detachment of the retina, but in such cases the boundary line between the blind and the seeing portions of the field hardly ever coincides with the middle of the field, and is generally irregular, while the condition is usually uni-ocular. Although such a condition might be called hemiopia of one eye, and was formerly frequently so designated, it is now more usual to speak in such a case of a loss of the upper or lower portion of the visual field, etc., and to restrict the term hemiopia to cases in which the line of separation is vertical or nearly so, and nearly bisects the field. The terms hemianopia, hemianopsia, hemiopia, are used indifferently to express the same condition, and with English writers hemiopia is the favourite. Since hemianopia or hemianopsia means that one half of each visual field is blind, the terms left, right, temporal, and nasal hemianopia would respectively indicate that there was loss of function over the portions of the field named. The term hemiopia, or half sight, is, it must be remembered, used in exactly the same way, and although the word itself does not, as in the previous instance, indicate it, "left hemiopia," etc., also means a loss of the half of the field named. The term "homonymous hemianopsia," is sometimes used to express the fact that in both the fields the defect is to the same side of the middle line, and "crossed hemianopsia" to indicate a bilateral, temporal, or nasal, defect. "Complete hemianopsia" means that the entire half of the field is affected; the term "absolute," that the blindness over the affected area is total. Another term, which is of comparatively recent origin, is "word-blindness" (alexia, or dyslexia) a condition in which with perfect vision there is an inability to comprehend the meaning of word-symbols; obviously this is closely allied to aphasia, but not neccessarily associated with it. (British Medical foumal 1887;ii:81.) 